\title{
Natural Immunoglobulins (Contribution to a Debate on Biomedical Education)
}

\author{
Nelson M Vaz \\ Departamento de Bioquímica e Imunologia, ICB, Universidade Federal de Minas Gerais, Caixa Postal 486, \\ 30161-970 Belo Horizonte, MG, Brasil
}

\begin{abstract}
Immunology has contributed to biomedical education in many important ways since the creation of scientific medicine in the last quarter of the 19th century. Today, immunology is a major area of biomedical research. Nevertheless, there are many basic problems unresolved in immunological activities and phenomena. Solving these problems is probably necessary to devise predictable and safe ways to produce new vaccines, treat allergy and autoimmune diseases and perform safe transplants. This challenge involves not only technical developments but also changes in attitude, of which the most fundamental is to abandon the traditional stimulus-response perspective in favor of more "systemic" views. Describing immunological activities as the operation of a complex multiconnected network, raises biological and epistemological issues not usually dealt with in biomedical education.

Here we point to one example of systemic approaches. A new form of immunoblot (Panama blot), by which the reaction of natural immunoglobulins with complex protein mixtures may be analyzed by a special software and multivariate statistics, has been recently used to characterize human autoimmune diseases. Our preliminary data show that Panama blots can also be used to characterize global (systemic) immunogical changes in chronic human parasitic diseases, such as malaria and schistosomiasis mansoni, that correlate with the clinical status.
\end{abstract}

Key words: immunology - immunoblot - natural antibodies - autoimmunity - parasites - malaria

The major change introduced by Freud and his followers in psychotherapy was to let their patients talk, instead of talking to them. I wonder what a similar attitude would do to immunology, i.e., if immunologists approached a mouse or a human organism without presuposing what it is responding to - what would they find? Can we study immunology without studying (specific immune) responses to (foreign, antigenic) stimuli? I claim that, yes, this can be done and that, indeed, can be very fruitful. But this requires a change in the way of seeing immunological activities and this is not easy to achieve. Let me first describe an example different from the one I will discuss in more details.

Natural immunoglobulins - In the late 80's, Coutinho and his colleagues produced many dozens of monoclonal immunologlobulins from the spleens of normal newborn BALB/c mice and analyzed the reactivities of these immunoglobulins. The

Supported by grants CNPq 5350349/93-0 and Fapemig $1516 / 96$.

Fax:+55-31-499.2640.E-mail:nvaz@ mono.icb.ufmg.br Received 7 August 2000

Accepted 4 September 2000 problem they faced was quite different from the usual situation, in which monoclonal antibodies to a defined antigen are produced to be used in a defined way - as if they were specific biochemical reagents. Coutinho and his colleagues, on the other hand, were studying "natural immunoglobulins" as they emerge as components of newborn mice, and not as "antibodies" formed in response to specific antigens. In the production of hybridomas the hybrid cells neoplastic plasma cells fuse only to activated lymphocytes, but not to resting lymphocytes. Thus, the spectrum of reactivities of these natural immunoglobulins represent the normal, physiologic activity of the immune system of a newborn mouse. A quite interesting and important observation.

The question was: how to choose the antigens to test these reactivities? To make a long story short, Coutinho and his colleagues found that the natural immunoglobulins produced by newborn mice react, with variable binding affinities, to virtually everything, although each immunoglobulin had a well defined profile of reactivity. They reacted with nominal antigens (like ovalbumin, haemocyanin, etc.) but also with self-components (mouse tissue extracts) including with other natural immunoglobulins of the same collection (Holmberg et al. 1984, Stewart \& Varela 1989). About one fifth of the immunoglobulins were "multispecific", in the sense 
that each of them reacted with a wide (but defined) collection of different substances, including other immunoglobulins (Ternynck \& Avrameas 1986, Araujo et al. 1987). This multireactivity forms a network of immunoglobulins early in the operation of the immune system and interference with their formation results in distortions of the adult $\mathrm{B}$ cell repertoire (Vakil et al. 1986). Human neonates also form many autoantibodies (Barbouche et al. 1992). Multispecific immunoglobulins are no longer present in the serum of adult mice (Holmberg et al. 1986).

Natural antibodies are frequently autoantibodies, both in mice (Cunningham 1974, Dresser 1978, Steele \& Cunningham 1978, Dighiero et al. 1985) and humans (Dighiero et al. 1982, 1986, Barbouche et al. 1992) and this autoreactivity provides a connectivity which is essential for the organization of the immune system (Coutinho et al. 1995, Lacroix-Desmazes et al. 1998) as predicted by Jerne (1974).

Three surprising findings on "natural immunoglobulins" - Surprisingly, the formation of "natural immunoglobulins", specially that of IgM is not the result of (specific immune) responses to (antigenic) stimuli. This is demonstrated by the relatively unaltered rate of $\operatorname{IgM}$ production in mice placed in germfree or antigen-free conditions. Antigen-free animals are germfree animals fed with lowmolecular weigh chemically defined diets. On the other hand, the formation of IgG and IgA is severely hindered in germfree mice and virtually abolished in antigen-free mice. What goes on in IgM formation, and to a certain extent, also in $\operatorname{IgG}$ (and $\operatorname{Ig} \mathrm{A}$ and $\mathrm{IgE}$ ) formation, seems to depend more on mechanisms "internal" to the animal and not to the interaction with external antigens (Holmberg et al. 1984, Bos et al. 1988).

A second surprising finding in "natural" IgM formation is that every mouse or human being establishes a particular spectrum of $\operatorname{IgM}$ formation early in life and, unless very severely disturbed e.g., by autoimmune diseases - maintains this spectrum, profile or pattern unaltered. This means that the patterns are maintained constant in spite of continuous exposure of the organism to different sorts of antigens, for example, food antigens and incidental infections by germs and virus (Haury et al. 1997). These patterns are analyzed in modified Western-blots (Panama blot) (Nóbrega et al. 1993a, b, Haury et al. 1994) in which normal serum reacts with complex mixtures of proteins separated in SDSPAGE, forming multiple bands; the results are then treated by a special software and analyzed by multivariate statistics (Principal Component Analysis).
A third surprising finding is the emergence of a whole array of new reactivities in preparations of $\mathrm{IgG}$ isolated from serum - specificities that disappear if the $\mathrm{IgG}$ is mixed back into the serum from which it was isolated. Serum IgM (Adib et al. 1990) and apparently also other serum components (Hurez et al. 1997), may neutralize these neoreactivities. For example, human ABO isohemagglutinins are complementary to the antigens expressed on red cells: A+ individuals form anti-B agglutinins, and vice-versa. But in IgG isolated from $\mathrm{A}+$ or $\mathrm{B}+$ individuals, both anti-A and anti-B agglutinins are present (Spalter et al. 1999).

The constancy of IgM profiles in spite of continuous antigenic stimulation (Haury et al. 1997) is rather unexpected. These findings are amazing and still in need of further investigation. For example, although the pattern of IgM remains unchanged and also IgG displays only minor changes during normal human pregancy (Mouthon et al. 1998), "antigen-free" mice, which produce very little IgG and IgA, increase IgG formation very substantially during pregnancy. This increase could only be due to pregnancy since all environmental antigenic influences are excluded in antigen-free mice (Bos et al. 1986). Recent observations on IgM and IgG of newborn, young and adult horses, also show a remarkable stability of IgM profiles and relatively little change in IgG profiles (Silva Neto et al. 2000).

Whatever these observations mean, they are of paramount importance. They affect the doctrine that specific antibodies arising in response to immunogenic stimuli are the essence of immunological activity. If immunoglobulin production is not guided (specified) directly and independently by external immunogens, but rather derives from an internal dynamics that forms enduring and interconnected patterns, this belief is misleading. Furthermore, the "hidden" reactivities emerging in purifield IgG may be telling us that a whole century of serological observations made with whole serum, does not show us the whole story, or worse, may be telling us another story, not the one important to the system itself.

If "natural antibodies" resulted from immune responses to accidental encounters with immunogens, no stable profiles of immunoglobulins would exist. But these stable profiles arise early in the lives of both mice (Nóbrega et al. 1996) and humans (Lacroix-Desmazes et al. 1995, Mouthon et al. 1996). These profiles remain stable in face of continuous contact with different immunogens. On the other hand, the profiles suffer significant and characteristic alterations in a number of human autoimmune diseases (Ferreira et al. 1997, Sundblad et al. 1997, Lacroix-Desmazes et al. 1997, 1999). This 
indicates that these diseases do not result from the isolated activities of "forbiden clones", but rather depend on global changes in the connectivity among lymphocytes.

Autoimmune pathology as pathogenic Eigenstates of the immune system - According to Jerne (1974), the operation of the immune system is characterized by Eigen-behaviours, and autoimmune diseases would be expressions of pathogenic Eigen-states of the immune sytem, i.e., particular patterns of connectivity leading to tissue damage. The alterations in Panama-blot profiles recently characterized in human autoimmune diseases (Ferreira et al. 1997, Sundblad et al. 1997, LacroixDesmazes et al. 1997, 1999) would be semi-quantitative records of these alterations.

In preliminary experiments, we tested whether it was possible to obtain similar records in different forms of chronic human parasitic diseases, such as Chagas disease and schistosomiasis mansoni, in which only a small proportion of infected individuals display severe symptoms. We analyzed anti-IgM and anti-IgG Panama blots of human sera reacting against an SDS-PAGE of an extract of Escherichia coli chosen at random. In malaria, the IgM profiles of 80 sera, mainly of gold prospectors working in Mato Grosso, permitted the separation of the reactivity to $E$. coli of individuals nonexposed or recently infected with malaria from those living in the same area but resistant to infection (normal endemics), those with symptoms of multiple malaria episodes, and also from those which turn "asymptomatic" after multiple malaria episodes. In addition, in a sample of 40 sera from subjects living in an endemic area of schistosomiasis nearby Belo Horizonte, significant differences in reactivity to the E. coli extract were present among sera from non-exposed subjects, intestinal, hepatointestinal and hepatosplenic subjects.

\section{CONCLUSION}

Panama blots inaugurate a new approach to the analysis of immunological activity that search for systemic regularities (profiles) rather than specific antibodies produced in immune responses. Similarly to what happens in human autoimmune diseases, Panama blot profiles also are to characterize patterns of natural immunoglobulins that arise in chronic human parasitic diseases according to the symptomatology.

\section{REFERENCES}

Adib MJ, Ragimbeau S, Avrameas S, Ternynck T 1990. $\mathrm{IgG}$ autoantibody activity in normal mouse serum is controlled by IgM. J Immunol 145: 3807-3813.

Araujo PMF, Holmberg D, Martinez AC, Coutinho A 1987. Idiotipic multireactivity of natural antibodies Natural anti-Idiotypes also inhibit helper cells with cross-reactive clonotypes. Scand J Immunol 25: 497505.

Barbouche R, Forveille M, Fischer A, Avrameas S, Durandy A 1992. Spontaneous IgM autoantibody production in vitro by B lymphocytes of normal human neonates. Scand J Immunol 35: 659-667.

Bos NA, Benner R, Wostmann BS, Pleasants JR 1986. 'Background' Ig-secreting cells in pregnant germfree mice fed a chemically defined ultrafiltered diet. $J$ Reprod Immunol 9: 237-246.

Bos NA, Meeuwsen CG, Wostmann BS, Pleasants JR, Benner R 1988. The influence of exogenous antigenic stimulation on the specificity repertoire of background immunoglobulin-secreting cells of different isotypes. Cell Immunol 112: 371-380.

Coutinho A, Kazatchkine MD, Avrameas S 1995. "Natural antibodies". Curr Op Immunol 7: 812-818.

Cunningham AJ 1974. Large number of cells in normal mice produce antibody to components of isologous erytrocytes. Nature 252: 749-751.

Dighiero G, Guilbert B, Avrameas 1982. Naturally occuring antibodies against nine common antigens in human sera. II. Highincidence of monoclonal Ig exhibiting antibody activity against actin and tubulin and shatring antibody specificity with natural antibodies. J Immunol 128: 2788-2792.

Dighiero G, Lymberi P, Holmberg D, Lundquist I, Coutinho A, Avrameas S 1985. High frequency of natural autoantibodies in normal newborn mice. $J$ Immunol 134: 765-772.

Dighiero G, Lymberi P, Guilbert B, Ternyck T, Avrameas S 1986. Natural autoantibodies constitute a substancial part of normal circulating immuno-globulins. Ann N Y Acad Sci 475: 135-138.

Dresser DW 1978. Most IgM-producing cells in the mouse secrete auto-antibodies (rheumatoid factor). Nature 274: 480-483.

Ferreira C, Mouthon L, Nobrega A, Haury M, Kazatchkine MD , Ferreira E, Padua F, Coutinho A, Sundblad A 1997. Instability of natural antibody repertoires in systemic lupus erythematosus patients, revealed by multiparametric analysis of serum antibody reactivities. Scand J Immunol 45: 33141.

Haury M, Grandien A, Sundblad A, Coutinho A, Nobrega A 1994. Global analysis of antibody repertoires. I. An immunoblot method for the quantitative screening of a large number of reactivities. Scand J Immunol 39: 79-87.

Haury M, Sundblad A, Grandien A, Barreau C, Coutinho A, Nobrega A 1997. The repertoire of serum IgM in normal mice is largely independent of external antigenic contact. Eur J Immunol 27: 1557-63.

Holmberg D, Forsgren S, Ivars F, Coutinho A 1984. Reactions among IgM antibodies derived from normal, neonatal mice. Eur J Immunol 14: 435-441.

Holmberg D, Wennerstrom G, Andrade L, Coutinho A 1986. The high idiotypic connectivity of "natural" newborn antibodies is not found in adult mitogenreactive B cell repertoires. Eur J Immunol 16: 82-87.

Hurez V, Kazatchnime MD, Vassilev T, Ramanathaan S, Pashov A, Basuyaux B, de Kosak Y, Bellon B, Kaveri 
SV 1997. Pooled normal human polyspecific IgM contains neutralizing idiotypes to IgG autoantibodies of autoimmune patients and protect from experimental autoimmune disease. Blood 90: 4004-4013.

Jerne NK 1974. Towards a network theory of the immune system. Ann Immunol (Paris) 125C: 373-389.

Lacroix-Desmazes S, Kaveri S, Mouthon L, Ayouba A, Malanchere E, Coutinho A, Kazatchkine MD 1998. Self-reactive antibodies (natural autoantibodies) in healthy individuals. J Immunol Meth 216: 117-137

Lacroix-Desmazes S, Mouthon L, Coutinho A, Kazatchkine MD 1995. Analysis of the human natural IgG antibody repertoire: life-long stabilitiy of reactivities toward self-antigens contrasts with agedependent diversification of reactivities against bacterial antigens. Eur J Immunol 25: 2598-2604.

Lacroix-Desmazes S, Mouthon L, Pashov A, Barreau C, Kaveri SV, Kazatchkine MD 1997. Analysis of antibody reactivities toward self antigens of IgM of patients with Waldenstrom's macroglobulinemia. Int Immunol 9: 1175-83.

Lacroix-Desmazes S, Resnick I, Stahl D, Mouthon L, Espanol T, Levy J, Kaveri SV, Notarangelo L, Eibl M, Fischer A, Ochs H, Kazatchkine MD 1999. Defective self-reactive antibody repertoire of serum IgM in patients with hyper-IgM syndrome. $J$ Immunol 162: 5601-5608.

Mouthon L, Lacroix-Desmazes S, Nobrega A, Barreau C, Coutinho A, Kazatchkine MD 1996. The selfreactive antibody repertoire of normal human serum $\operatorname{IgM}$ is acquired early in childhood and remains conserved throughout life. Scand J Immunol 44: 243 251.

Mouthon L, Lacroix-Desmazes S, Kazatchkine MD 1998. Analysis of self-reactive antibody repertoires in normal pregnancy. J Autoimmun 11: 279-286.

Nobrega A, Haury M, Grandien A, Malanchere E, Sundblat A, Coutinho A 1993b. Global analysis of antibody repertoires. II. Evidence for specific, self- selection and the immunological "homunculus" of antibodies in normal serum. Eur J Immunology 23: 2851-2859.

Nobrega A, Haury M, Grandien A, Sundblad A, Coutinho A 1993a. The "immunculus" of the natural history of the individual's molecular composition. In Y Schoenfeld, Natural Antibodies, Chap. 18, p. 295301.

Nobrega A, Haury M, Gueret R, Coutinho A, Weksler ME 1996. The age-associated increase in autoreactive immunoglobulins reflects a quantitative increase in specificities detectable at lower concentrations in young mice. Scand J Immunol 44: 437-443.

Silva Neto AC, Gontijo C, Vaz N, Fesel C 2000. Perfis de IgM e IgG naturais eqüinos. In XV Reunião da Fesbe, Caxambu, MG.

Spalter SH, Kaveri SV, Bonnin E, Mani JC, Cartron JP, Kazatchkine MD 1999. Normal human serum contains natural antibodies reactive with autologous ABO blood group antigens. Blood 93: 4418-4424.

Steele EJ, Cunningham AJ 1978. High proportion of Igproducing cells making autoantibody in normal mice. Nature 274: 483-484.

Stewart J , Varela F 1989. Exploring the meaning of connectivity in the immune network. Immunol Rev 110: 37-62.

Sundblad A, Ferreira C, Nobrega A, Haury M, Ferreira E, Padua F, Coutinho A 1997. Characteristic generated alterations of autoantibody patterns in idiopathic thrombocytopenic purpura. J Autoimmun 10: 193-201.

Ternynck T, Avrameas S 1986. Murine natural monoclonal autoantibodies: a study of their polyspecificities and their affinities. Immunol Rev 94: 99-111.

Vakil M, Sauter J, Paige C, Kearney JF 1986. In vivo suppression of perinatal multispecific B cell results in a distortion of adult B cell repertoire. Eur $J$ Immunol 16: 1159-1165. 